\title{
Comparison of perfusion and thickening between vein and right internal thoracic artery composite grafts from a randomized trial substudy
}

\author{
Ho Young Hwang, MD, PhD, ${ }^{\mathrm{a}}$ Jin Chul Paeng, MD, PhD, ${ }^{\mathrm{b}}$ Hong Chul Oh, MD, ${ }^{\mathrm{a}}$ Yong Han Kim, MD, ${ }^{\mathrm{a}}$ and \\ Ki-Bong Kim, MD, $\mathrm{PhD}^{\mathrm{a}}$
}

\begin{abstract}
Background: Improvements in myocardial perfusion and thickening were compared in coronary artery bypass grafting patients who received saphenous vein (SV) Y-composite grafts versus those who received right internal thoracic artery ([R]ITA) Y-composite grafts.

Methods: Of the 224 patients enrolled in a randomized clinical trial, 116 patients ( $\mathrm{SV}$ group, $\mathrm{n}=65$; RITA group, $\mathrm{n}=51$ ) in whom myocardial single-photonemission computed tomography was performed preoperatively, and at 3 months and 1 year postoperatively, were retrospectively studied. A 20-segment model was adopted, and a total of 792 ischemic myocardial segments (SV group, $\mathrm{n}=443$; RITA group, $\mathrm{n}=349$ ) were analyzed. The reversibility score (rest minus stress perfusion value) as an indicator of ischemic myocardium, and Z-values for segmental myocardial thickening, were calculated.
\end{abstract}

Results: Compared with preoperative values, both myocardial perfusion and segmental myocardial thickening had improved significantly at 3 months and 1 year postoperatively (reversibility scores [mean \pm SD] were, respectively: $13.5 \pm 8.0$ vs $5.8 \pm 6.2$ and $5.1 \pm 6.2, P<.001 ; Z$-values were $-1.13 \pm 1.53$ vs $-0.62 \pm 1.40$ and $-0.67 \pm 1.35, P<.001)$. Mixed-effect model analyses showed no differences in improvements in myocardial perfusion and segmental myocardial thickening between the 2 groups 1 year after revascularization. Separate analysis demonstrated less improvement of myocardial perfusion in the right coronary artery territory of the RITA group than the SV group, with marginal significance $(P=.056)$.

Conclusions: Improvements in myocardial perfusion and segmental myocardial thickening were similar between the 2 groups at 1 year after revascularization. The SV, versus the right ITA, composite graft may be more beneficial in perfusion improvement of the right coronary artery territory. (J Thorac Cardiovasc Surg 2015;150:1187-94)

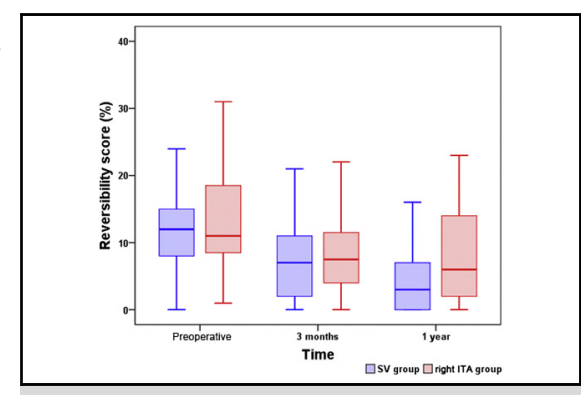

Improvement of myocardial perfusion (reversibility scores) in the right coronary artery territory.

\section{Central Message}

Improvements in myocardial perfusion and thickening at 1 year were similar after CABGs using the SV and right ITA as Y-composite grafts.

\section{Perspective}

An SV Y-composite graft was shown to be sufficient for CABG, in improvement in myocardial perfusion and thickening during the first postoperative year. The SV, versus the right ITA, composite graft may be more beneficial for perfusion improvement of the RCA territory.

See Editorial Commentary page 1195 .
The saphenous vein (SV) remains a conduit commonly used for coronary artery bypass grafting (CABG). However, low long-term patency rates and poor clinical outcomes after

\footnotetext{
From the Departments of ${ }^{\mathrm{a}}$ Thoracic and Cardiovascular Surgery, and ${ }^{\mathrm{b}}$ Nuclear Medicine, Seoul National University Hospital, Seoul National University College of Medicine, Seoul, Republic of Korea.

Received for publication April 7, 2015; revisions received July 29, 2015; accepted for publication Aug 1, 2015; available ahead of print Sept 15, 2015

Address for reprints: Ki-Bong Kim, MD, PhD, Department of Thoracic and Cardiovascular Surgery, Seoul National University Hospital, Seoul National University College of Medicine, 101 Daehak-ro, Chongno-gu, Seoul 110-744, Republic of Korea (E-mail: kimkb@snu.ac.kr).

$0022-5223 / \$ 36.00$

Copyright (c) 2015 by The American Association for Thoracic Surgery http://dx.doi.org/10.1016/j.jtcvs.2015.08.009
}

CABG using aortocoronary SV grafts have been limitations in the use of SV conduits. ${ }^{1-3}$ Recent studies have revealed that using the minimal manipulation technique during SV harvesting improved the long-term patency of SV grafts by preserving the SV wall structure, particularly the endothelial layer. ${ }^{4,5}$

A recent randomized clinical trial ${ }^{6,7}$ (a comparison of the $\mathrm{SV}$ vs right internal thoracic artery ([R]ITA) as a Ycomposite graft [SAVE RITA]), designed to compare the $\mathrm{SV}$ (SV group, $\mathrm{n}=112$ ) with the right ITA (RITA group, $\mathrm{n}=112$ ) used as a Y-composite graft based on the in situ left ITA in off-pump CABG patients, further demonstrated that minimally manipulated SV composite grafts were not 


$\begin{array}{rlrl}\text { Abbreviations and Acronyms } \\ \text { CABG } & =\text { coronary artery bypass grafting } \\ \text { CI } & =\text { confidence interval } \\ \text { LAD } & =\text { left anterior descending coronary } \\ & \text { artery } \\ \text { LCX } & =\text { left circumflex coronary artery } \\ \text { MIBI } & =\text { methoxyisobutylisonitrile } \\ \text { RCA } & =\text { right coronary artery } \\ \text { RITA } & =\text { right internal thoracic artery } \\ \text { SAVE RITA = } & \text { saphenous vein versus right internal } \\ & \text { thoracic artery as a Y-composite } \\ & \text { graft } \\ \text { SPECT } & =\text { single-photon-emission computed } \\ & \text { tomography } \\ \text { SV } & =\text { saphenous vein }\end{array}$

inferior to right ITA composite grafts in either graft patency rate at 1 year or midterm clinical outcomes. ${ }^{6,7}$ The aim of the current study was to compare improvements in segmental myocardial perfusion and thickening after off-pump CABG, using SV and right ITA Y-composite grafts in a subgroup of patients who were enrolled in the SAVE RITA trial.

\section{METHODS \\ Patient Characteristics}

The study protocol was reviewed by the institutional review board and approved as a minimal-risk retrospective study (approval no. $\mathrm{H}$ 1308-034-509) that did not require individual consent according to the institutional guidelines for waiving consent. Five of the 224 eligible patients who were enrolled in the SAVE RITA trial were withdrawn immediately because of an intraoperative protocol violation. Of the 219 patients who underwent operation as planned for the SAVE RITA trial, 116 patients were studied (65 in the SV group; 51 in the RITA group) in whom myocardial single-photon-emission computed tomography (SPECT) tests were performed preoperatively, and at 3 months and 1 year postoperatively. Inclusion criteria included (1) patients whose graft patency was confirmed by means of coronary angiography performed 1 year postoperatively, and (2) patients in whom both the resting and stress myocardial SPECT were performed preoperatively, and at 3 months and 1 year postoperatively. Coronary angiograms were performed at 1 year, according to the protocol of the randomized trial. ${ }^{6}$

Serial myocardial SPECT studies were not included in the protocol of our randomized controlled trial but were performed as a part of the routine postoperative evaluation protocol at our institution. Patients were excluded who did not receive both the resting and stress myocardial SPECT $(n=52)$, received a conduit in addition to the SV or right ITA $(n=37)$, or either refused to undergo the 1-year angiographic follow-up examination or showed occluded grafts at follow-up angiography $(\mathrm{n}=14$; Figure 1$)$. More patients in the RITA group were men and had a history of stroke than in the SV group, with marginal significances $(P=.069$ and $P=.051$, respectively) (Table 1). Demographic data of the patients who were enrolled in the present study were not statistically different from those of the other 108 patients who were excluded (Table 2).

\section{Operative Techniques and Revascularization Strategies}

The basic surgical procedures and principles of off-pump CABG and the technique for harvesting the SV have been previously described. ${ }^{7}$ The left and right ITAs were both harvested using a skeletonization technique. The SV was harvested from a lower leg after systemic heparinization. The manipulation and tension of the SV were minimized during harvest, and manual dilatation and intraluminal flushing were avoided. Immediately after the second limb conduit (SV or right ITA) was harvested, it was anastomosed to the side of the left ITA in a Y fashion.

The left anterior descending coronary artery (LAD) territory was revascularized first, using the left ITA in all study patients. Next, the left circumflex coronary artery (LCX) territory was revascularized, followed by the right coronary artery (RCA) territory. Both the LCX and RCA territories were revascularized using the second limb conduit (SV in the SV group and right ITA in the RITA group), using a sequential anastomotic technique. The average number of distal anastomoses per patient was similar for the SV versus ITA group, respectively: $(3.5 \pm 0.9$ vs $3.5 \pm 0.7 ; P=.635)$; for both the left ITA $(1.3 \pm 0.5$ vs $1.3 \pm 0.5$; $P=.779)$, and the second limb conduit ( $2.2 \pm 0.8$ vs $2.1 \pm 0.6 ; P=.523)$.

The patients were given an initial dose of heparin $(1.5 \mathrm{mg} / \mathrm{kg})$ and periodic supplemental doses, to maintain an activated clotting time of $>300$ seconds. All patients took aspirin until the day of surgery and resumed it as soon as possible, usually at 1 day postoperatively. If the patient had a high blood level of low-density lipoprotein cholesterol $(>100 \mathrm{mg} / \mathrm{dL})$, statin medication was started.

\section{Myocardial Single-Photon-Emission Computed Tomography}

Thallium-201 rest/adenosine stress technetium-99m-methoxyisobutylisonitrile (MIBI)-gated SPECT was performed in all study patients. ${ }^{8}$ Thallium-201 (111 MBq) was injected at rest, and SPECT was performed. Coronary perfusion reserve was assessed by infusing adenosine $(0.84 \mathrm{mg} /$ $\mathrm{kg}$ ) for 6 minutes, to induce stress; technetium-99m-MIBI (370 MBq) was injected 3 minutes after the start of adenosine infusion. Gated technetium99m-MIBI SPECT was performed 90 minutes after stress, using a dualhead camera equipped with low-energy, high-resolution collimators (CardioMD; Philips Medical Systems, Milpitas, Calif). Thallium-201 rest/adenosine stress technetium-99m-MIBI-gated SPECT was repeated 3 months (92 \pm 16 days) and 1 year (13.9 \pm 2.1 months) after off-pump $\mathrm{CABG}$, as a follow-up examination, by using the same protocol as that used for the preoperative study.

\section{Quantification of Myocardial Regional Perfusion and Thickening}

A 20-segment model was adopted for regional analysis: 10 segments were subtended to the LAD territory, 6 to the LCX territory, and 4 to the RCA territory (Figure 2). ${ }^{9}$ The reconstructed images were analyzed using an automatic quantifying software package (AutoQUANT, Philips Medical Systems), after overall image quality was assessed by 2 experts. Resting and stress segmental myocardial perfusion was quantified by measuring radioactivity, and expressed as the percentage of the maximal radioactivity uptake.

The reversibility score, defined as a measure of rest minus stress perfusion values, was used as an indicator of the reversibility of perfusion impairment. The reversible myocardial segments were selected based on a cutoff value of 7 , suggesting a viable segment in terms of perfusion reversibility. ${ }^{8}$ A total of 792 ischemic myocardial segments (reversibility score $\geq 7$ ) were analyzed (443 in the SV group; 349 in the RITA group). The average number of analyzed segments per patient was $6.8 \pm 4.6$ $(3.5 \pm 2.7$ in the LAD territory, $2.4 \pm 1.7$ in the LCX territory, and $1.0 \pm 1.2$ in the RCA territory). No statistical differences were found in average number of myocardial segments analyzed between the 2 groups. 


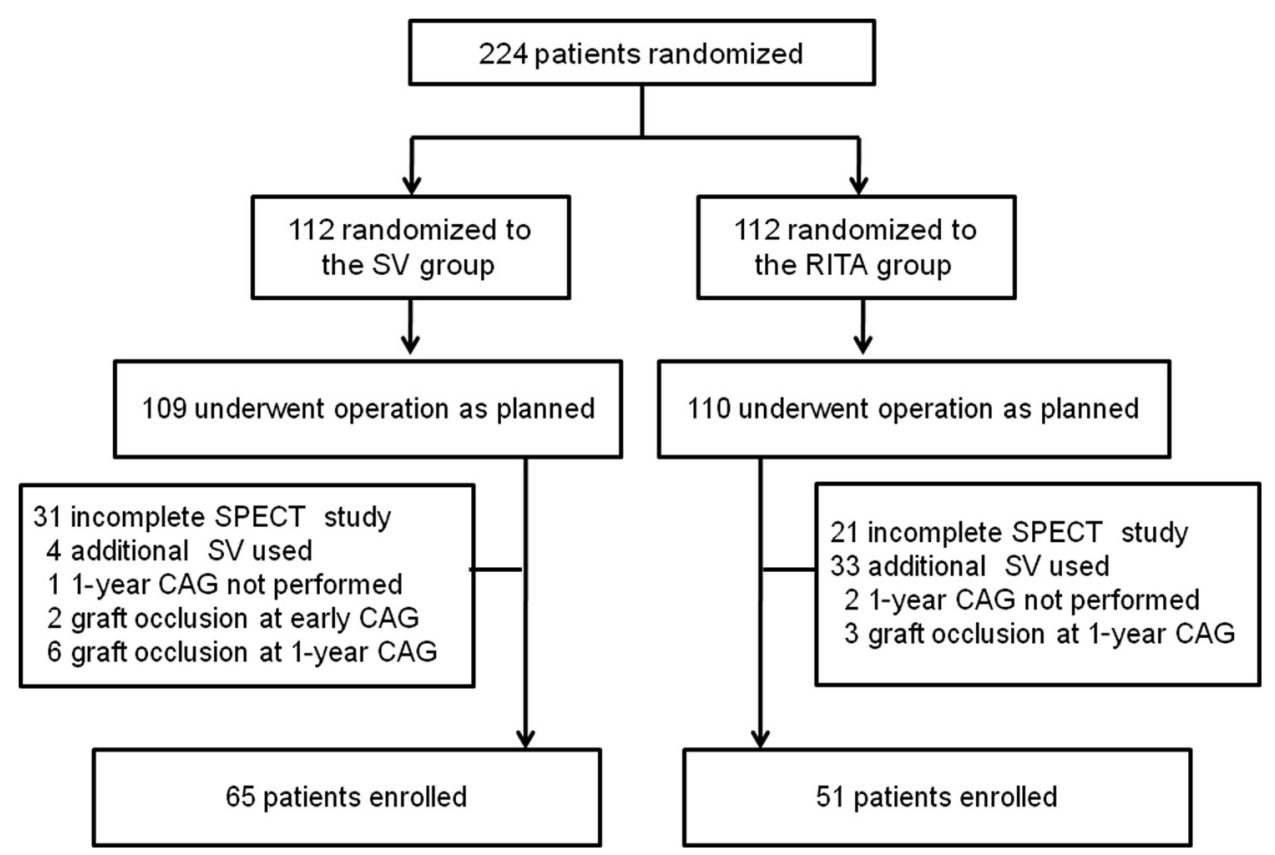

FIGURE 1. Summary flow diagram of patient enrollment. SV, Saphenous vein; RITA, right internal thoracic artery; SPECT, single-photon-emission computed tomography; $C A G$, coronary angiogram.

Segmental myocardial thickening was quantified by measuring percentage increments in myocardial thickness during the systolic phase. Because thickening values varied among myocardial segments, Z-values for myocardial thickening, defined as a measure of observed values minus reference values, divided by the $\mathrm{SD}$ of reference values, were used. ${ }^{10}$

TABLE 1. Comparison of preoperative characteristics and risk factors of the study patients

\begin{tabular}{|c|c|c|c|}
\hline Variables & $\begin{array}{c}\text { SV group } \\
(n=65)\end{array}$ & $\begin{array}{l}\text { RITA group } \\
\quad(\mathbf{n}=\mathbf{5 1})\end{array}$ & $\begin{array}{c}P \\
\text { value }\end{array}$ \\
\hline Age (y) & $63.2 \pm 7.9$ & $63.1 \pm 8.1$ & .933 \\
\hline Female & $18(27.7)$ & $7(13.7)$ & .069 \\
\hline \multicolumn{4}{|l|}{ Risk factors } \\
\hline Smoking & $32(49.2)$ & $31(60.8)$ & .215 \\
\hline Hypertension & $46(70.8)$ & $34(66.7)$ & .636 \\
\hline Diabetes mellitus & $30(46.2)$ & $22(43.1)$ & .746 \\
\hline Dyslipidemia & $9(13.8)$ & $4(7.8)$ & .309 \\
\hline Overweight (BMI $\geq 25 \mathrm{~kg} / \mathrm{m}^{2}$ ) & $37(56.9)$ & $22(43.1)$ & .140 \\
\hline History of stroke & $4(6.2)$ & $9(17.6)$ & .051 \\
\hline Unstable angina & $46(70.8)$ & $40(78.4)$ & .350 \\
\hline \multicolumn{4}{|l|}{ Angiographic diagnosis } \\
\hline Left main disease & $23(35.4)$ & $21(41.2)$ & .523 \\
\hline Three-vessel disease & $50(76.9)$ & $38(74.5)$ & .763 \\
\hline Logistic EuroSCORE (\%) & $3.1 \pm 2.6$ & $3.2 \pm 2.3$ & .872 \\
\hline LVEF ( $\%$, by echocardiography) & $57.1 \pm 10.1$ & $57.1 \pm 8.7$ & .964 \\
\hline LVEF $(\%$, by myocardial SPECT) & $54.8 \pm 12.0$ & $56.2 \pm 9.9$ & .514 \\
\hline
\end{tabular}

\section{Statistical Analysis}

Statistical analysis was performed using SAS version 9.1 (SAS Institute, Inc, Cary, NC) and SPSS version 12.0 (SPSS, Inc, Chicago, Ill). Comparisons between the 2 groups were made using $\chi^{2}$ analysis or the Fisher exact test for categoric variables, and the Student $t$ test for continuous variables. The mixed models, using fixed (type of second conduit, postoperative period of SPECT study, coronary artery territory, and number of distal anastomoses) and random (patients) effects, were used to compare

TABLE 2. Preoperative characteristics and risk factors of the study patients and those excluded from the study

\begin{tabular}{lccc}
\hline \multicolumn{1}{c}{ Variables } & $\begin{array}{c}\text { Study } \\
\text { patients } \\
(\mathbf{n = 1 1 6})\end{array}$ & $\begin{array}{c}\text { Excluded } \\
\text { patients } \\
(\mathbf{n}=\mathbf{1 0 8})\end{array}$ & $\begin{array}{c}\boldsymbol{P} \\
\text { value }\end{array}$ \\
\hline Age (y) & $63.1 \pm 8.0$ & $62.9 \pm 7.8$ & .840 \\
Female & $25(21.6)$ & $26(24.1)$ & .653 \\
Risk factors & & & \\
$\quad$ Smoking & $63(54.3)$ & $47(43.5)$ & .106 \\
Hypertension & $80(69.0)$ & $76(70.4)$ & .819 \\
$\quad$ Diabetes mellitus & $52(44.8)$ & $46(42.6)$ & .736 \\
$\quad$ Dyslipidemia & $13(11.2)$ & $20(18.5)$ & .123 \\
$\quad$ Overweight (BMI $\left.\geq 25 \mathrm{~kg} / \mathrm{m}^{2}\right)$ & $59(50.9)$ & $44(40.7)$ & .129 \\
$\quad$ History of stroke & $13(11.2)$ & $18(16.7)$ & .237 \\
$\quad$ Unstable angina & $86(74.1)$ & $81(75.0)$ & .882 \\
Angiographic diagnosis & & & \\
$\quad$ Left main disease & $44(37.9)$ & $40(37.0)$ & .890 \\
$\quad$ Three-vessel disease & $88(75.9)$ & $89(82.4)$ & .229 \\
Logistic EuroSCORE $(\%)$ & $3.2 \pm 2.4$ & $3.4 \pm 2.7$ & .589 \\
LVEF (\%, by echocardiography) & $57.1 \pm 9.5$ & $57.1 \pm 9.5$ & .995 \\
\hline
\end{tabular}

BMI, Body mass index; EuroSCORE, European System for Cardiac Operative Risk Evaluation; $L V E F$, left ventricular ejection fraction. 


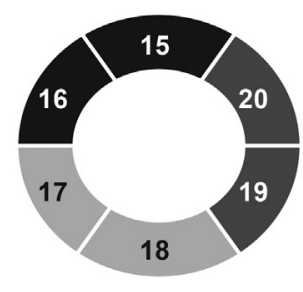

Basal

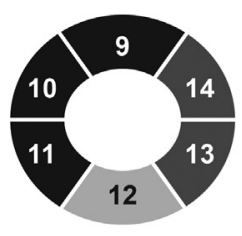

Mid

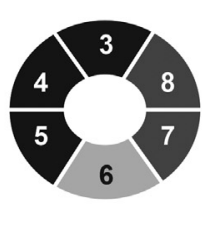

Apical

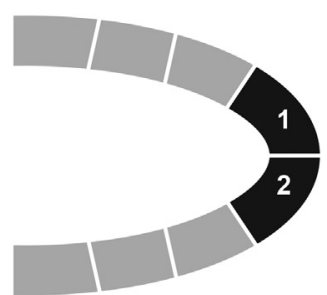

Apex

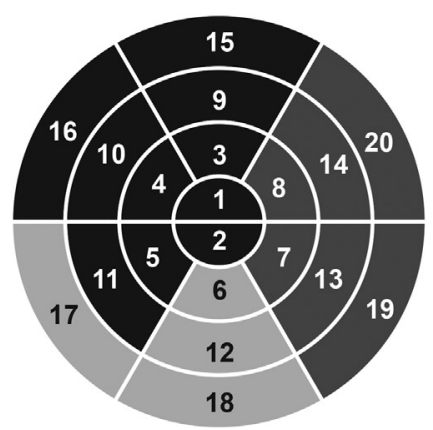

LAD

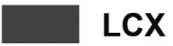

FIGURE 2. A 20-segment model for analysis of results of the myocardial single-photon-emission computed tomography. $L A D$, Left anterior descending coronary artery; $L C X$, left circumflex coronary artery; $R C A$, right coronary artery.

changes in reversibility scores and Z-values between the 2 groups. SAS PROC MIXED was used for the mixed-model analyses. The normality assumption of model residuals was checked, using histograms and normal quantile-quantile plots of residuals.

The significance of all possible interaction terms was tested, and significant interaction was included in the mixed model. The interaction between the periods of the SPECT study and coronary artery territory was significant in myocardial perfusion analysis, whereas the interaction between group and coronary artery territory was significant in the myocardial thickening analysis. However, interaction between groups and postoperative times was not significant in either mixed model.

Further analyses according to the coronary artery territories were performed using the mixed model with fixed (type of second conduit, postoperative period of SPECT study, and number of distal anastomoses) and random (patients) effects in the LCX and RCA territories where the second limb conduits were used. Data were expressed as the mean $\pm \mathrm{SD}$, or proportions, and $P$ values from mixed models were presented. A $P$ value was considered as statistically significant when it was $<.050$ and treated as marginally significant when between .050 to .100 .

\section{RESULTS}

\section{Improvements in Myocardial Perfusion}

Compared with the preoperative values, the reversibility scores decreased significantly at 3 months and at 1 year after operation $(13.5 \pm 8.0$ vs $5.8 \pm 6.2$, and $5.2 \pm 6.2 ; P<.001)$. When the preoperative reversibility scores were compared with the postoperative values according to coronary artery territories, the reversibility scores decreased significantly, at 3 months and at 1 year after operation, in all 3 territories of both groups. The preoperative scores, and those at 3 months and 1 year, respectively, were, for the LAD territory: $13.5 \pm 8.2 ; 4.8 \pm 5.8$; and $4.9 \pm 6.1 ; P<.001$ (SV group); and $12.5 \pm 8.3 ; 4.5 \pm 5.7 ;$ and $4.0 \pm 5.7$;
$P<.001$ (RITA group). For the LCX territory, the scores were: $15.1 \pm 8.3 ; 6.9 \pm 6.4$; and $6.5 \pm 6.5 ; P<.001$ (SV group); and $13.6 \pm 7.9 ; 6.7 \pm 7.1$; and $5.8 \pm 6.7$; $P<.001$ (RITA group). For the RCA territory, the scores were: $12.5 \pm 6.1 ; 7.4 \pm 5.9$; and $4.1 \pm 4.4 ; P<.001$ (SV group); and $13.4 \pm 7.5 ; 8.0 \pm 5.0 ;$ and $7.8 \pm 6.6$; $P<.001$ (RITA group) (Figure 3 ).

Mixed-effect models showed that absolute reversibility score values were higher in the LCX than in the LAD territories $(P=.005)$, and a significant interaction between the period of study and coronary artery territories was found; the reversibility score decrease in the RCA territory was significantly less than that in the LAD territory at 3 months $(\beta=3.174 ; P<.001)$. However, no differences were found in overall improvement of myocardial perfusion between the SV and RITA groups during the first postoperative year $(P=.455)$. In addition, myocardial perfusion improvement was not affected by number of distal anastomoses $(P=.893)$ (Table 3).

To analyze the area that was revascularized by the second conduit, further analyses in the LCX and RCA territories were performed using separate mixed-effect models. Myocardial perfusion improvement in the RITA group was not significantly different from that in the SV group in the LCX territory ( $\beta$ of the RITA group $=-0.32 ; 95 \%$ confidence interval $[\mathrm{CI}]:-2.02$ to $1.39 ; P=.715)$. In the RCA territory, however, myocardial perfusion improvement of the RITA group was less than that of the SV group, with marginal significance ( $\beta$ of the RITA group $=1.72 ; 95 \% \mathrm{CI}:-0.05$ to $3.49 ; P=.056)$. 

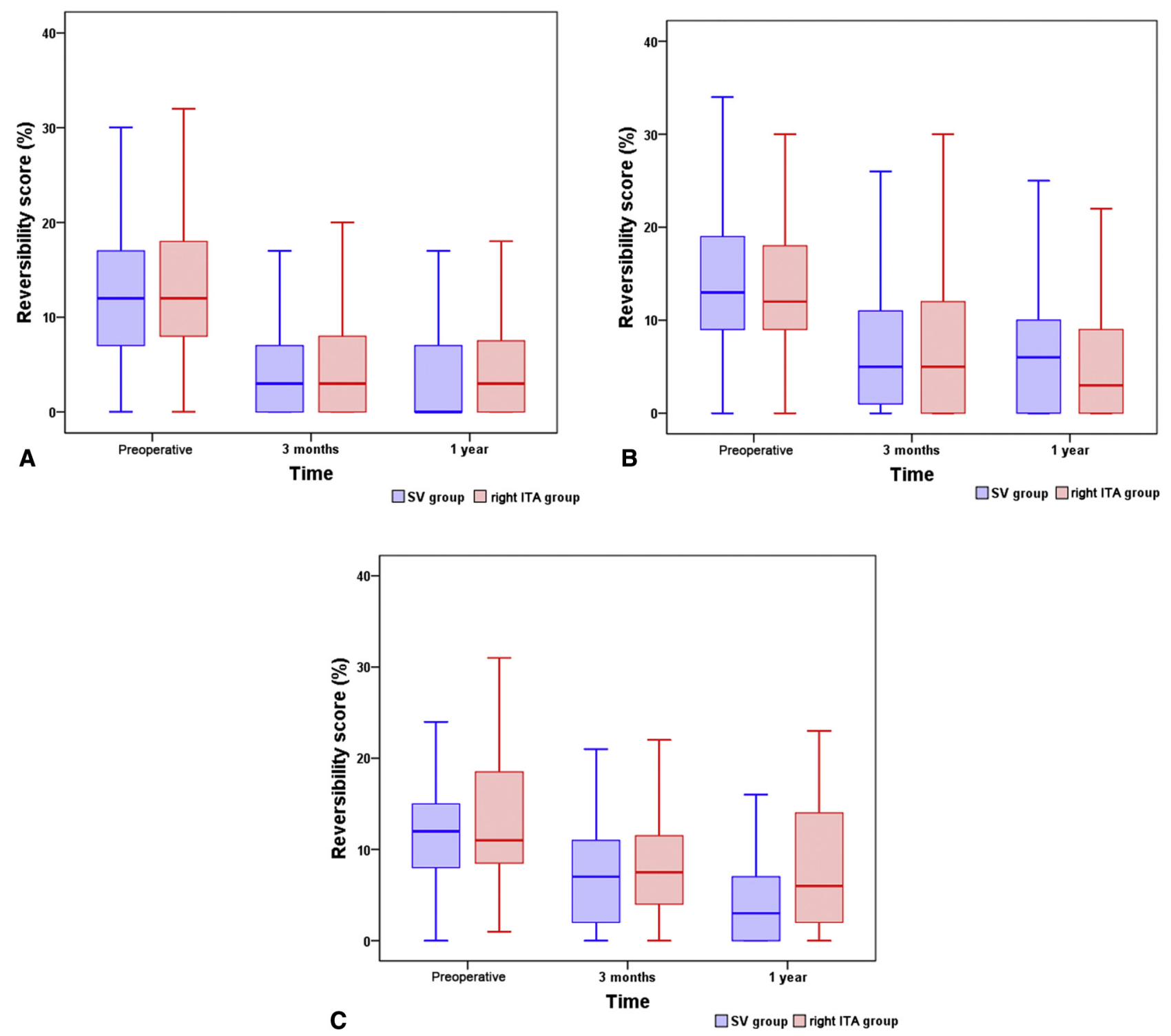

FIGURE 3. Improvement of myocardial perfusion (reversibility scores) in the (A) LAD; (B) LCX; and (C) RCA territories in the SV and RITA groups, preoperatively, and at 3 months and 1 year postoperatively. Mixed-effect models demonstrated that absolute reversibility score values were higher in the LCX than the LAD territories $(P=.005)$. In addition, the reversibility score changes in the RCA were significantly different from those in the LAD at 3 months $(P<.001)$. (The central box represents the values from the lower to the upper quartile, and the middle line represents the median. A line extends from the minimum to the maximum value). $S V$, Saphenous vein; ITA, internal thoracic artery.

\section{Improvements in Myocardial Thickening}

Postoperative Z-values for myocardial thickening increased significantly at 3 months $(-1.13 \pm 1.53$ vs $-0.64 \pm 1.36 ; P<.001)$, and remained unchanged until 1 year postoperatively $(-0.68 \pm 1.37)$. When the preoperative $\mathrm{Z}$-values were compared with the postoperative values, by coronary artery territories, Z-values increased significantly at 3 months and at 1 year after operation in the 3 territories of both groups. For the LAD territory, the values preoperatively, at 3 months, and at 1 year, respectively, for the SV group, were:
$-1.19 \pm 1.55 ;-0.68 \pm 1.41 ;$ and $-0.69 \pm 1.50 ; P<.001 ;$ for the RITA group, the values were: $-1.31 \pm 1.75$; $-0.91 \pm 1.35$; and $-0.84 \pm 1.33 ; P<.001$. For the LCX territory, the values for the SV group were: $-1.14 \pm 1.43$; $-0.69 \pm 1.21$; and $-0.75 \pm 1.26 ; P<.001$; the values for the RITA group were: $-0.91 \pm 1.38 ;-0.23 \pm 1.19$; and $-0.35 \pm 1.24 ; P<.001$. For the RCA territory, the values for the SV group were: $-0.92 \pm 1.38 ;-0.35 \pm 1.60$; and $-0.63 \pm 1.46 ; P<.001$; the values for the RITA group were: $-1.07 \pm 1.38 ;-0.90 \pm 1.31$; and $-0.83 \pm 1.28$; $P<.001$ (Figure 4). 
TABLE 3. Mixed-effect regression model on changes in reversibility score

\begin{tabular}{|c|c|c|c|}
\hline Variables & $\begin{array}{c}\text { Estimate } \\
(\beta)\end{array}$ & $95 \%$ CI & $\begin{array}{c}P \\
\text { value }\end{array}$ \\
\hline \multicolumn{4}{|l|}{ Type of conduit $(\mathrm{ref}=\mathrm{SV})$} \\
\hline RITA & -0.517 & -1.871 to 0.838 & .455 \\
\hline \multicolumn{4}{|l|}{ Time $($ ref $=$ preoperative period $)$} \\
\hline $3 \mathrm{mo}$ & -8.384 & -9.217 to -7.551 & $<.001$ \\
\hline $1 \mathrm{y}$ & -8.531 & -9.364 to -7.698 & $<.001$ \\
\hline Number of distal anastomoses & 0.044 & -0.595 to 0.683 & .893 \\
\hline \multicolumn{4}{|l|}{$\begin{array}{l}\text { Coronary artery territory } \\
\qquad(\text { ref }=\mathrm{LAD})\end{array}$} \\
\hline LCX & 1.395 & 0.432 to 2.358 & .005 \\
\hline RCA & 0.024 & -1.297 to 1.346 & .971 \\
\hline \multicolumn{4}{|l|}{ Time by coronary artery territory } \\
\hline $\mathrm{LCX}$ at $3 \mathrm{mo}$ & 0.752 & -0.551 to 2.055 & .258 \\
\hline $\mathrm{LCX}$ at $1 \mathrm{y}$ & 0.257 & -1.046 to 1.560 & .699 \\
\hline $\mathrm{RCA}$ at $3 \mathrm{mo}$ & 3.174 & 1.404 to 4.944 & $<.001$ \\
\hline RCA at $1 \mathrm{y}$ & 1.189 & -0.581 to 2.959 & .188 \\
\hline
\end{tabular}

$C I$, Confidence interval; ref, reference; $S V$, saphenous vein; RITA, right internal thoracic artery; $L A D$, left anterior descending coronary artery; $L C X$, left circumflex coronary artery; $R C A$, right coronary artery.

Mixed-effect models showed no differences in decrease of overall Z-values between the SV and RITA groups $(P=.477)$ (Table 4$)$. In addition, the effects of the number of distal anastomoses were not statistically significant $(P=.103)$.

Although a significant interaction was found between the type of conduit and coronary artery territories, the overall $\mathrm{Z}$-value increase in the LCX territory of the RITA group was not significantly different from that of the SV group (least-squares mean difference of 0.23 ; $95 \% \mathrm{CI}$ : -0.18 to $0.65 ; P=.273$ ). These results were additionally shown in the following analyses: Separate analyses in the LCX and RCA territories showed that improvements in the RITA group were not significantly different from those in the SV group in the LCX ( $\beta$ of the RITA group $=0.149 ; 95 \% \mathrm{CI}:-0.261$ to $0.558 ; P=.476)$ and RCA ( $\beta$ of the RITA group $=-0.379$; $95 \%$ CI: -0.964 to $0.206 ; P=.203$ ) territories.

\section{DISCUSSION}

This study demonstrates 2 main findings. First, improvements in myocardial perfusion and thickening during the first postoperative year did not differ significantly between the CABG patients who received SV, versus right ITA, Y-composite grafts. Second, SV, versus right ITA, composite grafts may have greater perfusion improvement in the RCA territory at 1 year after CABG.

Because of limitations of the SV as a vein conduit, and harmful effects from dilating it after harvest and exposing it directly to the ascending aortic flow and pressure, CABG using SV grafts resulted in low graft patency rates and poor long-term survival, compared with $\mathrm{CABG}$ using left ITA grafts. ${ }^{1-3}$ In addition, recent trials have demonstrated unsatisfactory patency rates for the SV $(89 \%$ at 1 year; $81.4 \%$ at 5 years) harvested with conventional methods and used as aortocoronary bypass grafts. $^{11,12}$

The resurgent surgical technique of minimizing manipulation of the SV during harvest, and preserving venous endothelium, is one effort to improve long-term patency of SV grafts. ${ }^{4,5}$ In addition, the theoretical benefits of using the SV as a composite graft based on the in situ left ITA are: (1) exposure of the SV to less circulatory stress than the one anastomosed to the ascending aorta; and (2) continuous exposure of the SV to endothelium-protective substances, such as endotheliumderived hyperpolarizing factor, and nitric oxide released from the in situ ITA. ${ }^{13-16}$ This second benefit, however, might be attenuated because the SV was anastomosed to the middle part of the left ITA, where the entire length of the ITA could not contribute to the potential effect.

The recent SAVE RITA randomized controlled trial demonstrated that the results of CABG using a minimally manipulated SV Y-composite graft based on the left ITA were not inferior to results of CABG using a right ITA Y-composite graft, in 1-year graft patency rates or 4-year clinical outcomes. ${ }^{7}$ The present study analyzed improvements of myocardial perfusion and thickening in CABG patients who were enrolled in the SAVE RITA trial and underwent myocardial SPECT, preoperatively and at 3 months and 1 year postoperatively. To minimize the impact of graft patency on the study results, we enrolled patients whose grafts were proven to be patent on 1-year coronary angiograms.

The present study demonstrated that myocardial perfusion and thickening improved until 1 year after surgery, a finding in agreement with previous studies. ${ }^{9,17}$ Mixed-effect models showed no differences in the overall improvement patterns of myocardial perfusion and thickening between the SV and RITA groups. The current study additionally showed that SV composite grafts were comparable with right ITA composite grafts in myocardial perfusion and thickening improvement.

In addition, separate analyses performed in the LCX and RCA territories (where revascularization was performed using the SV or right ITA) suggested that improvement of myocardial perfusion in the RCA territory might be greater in the SV group than in the RITA group, with marginal significance $(P=.056)$. When the right ITA is used as a Y-composite graft, a far distal portion of the right ITA is used for anastomosing the RCA territory. Because the distal end of the ITA is smaller in diameter and contains more smooth muscle cells, ${ }^{18,19}$ it is prone to vasospasm and may have less flow reserve for perfusion of the RCA territory than the large and endothelium-preserved SV conduit.

Limitations to the present study must be recognized. First, this study was retrospective, although patients were 

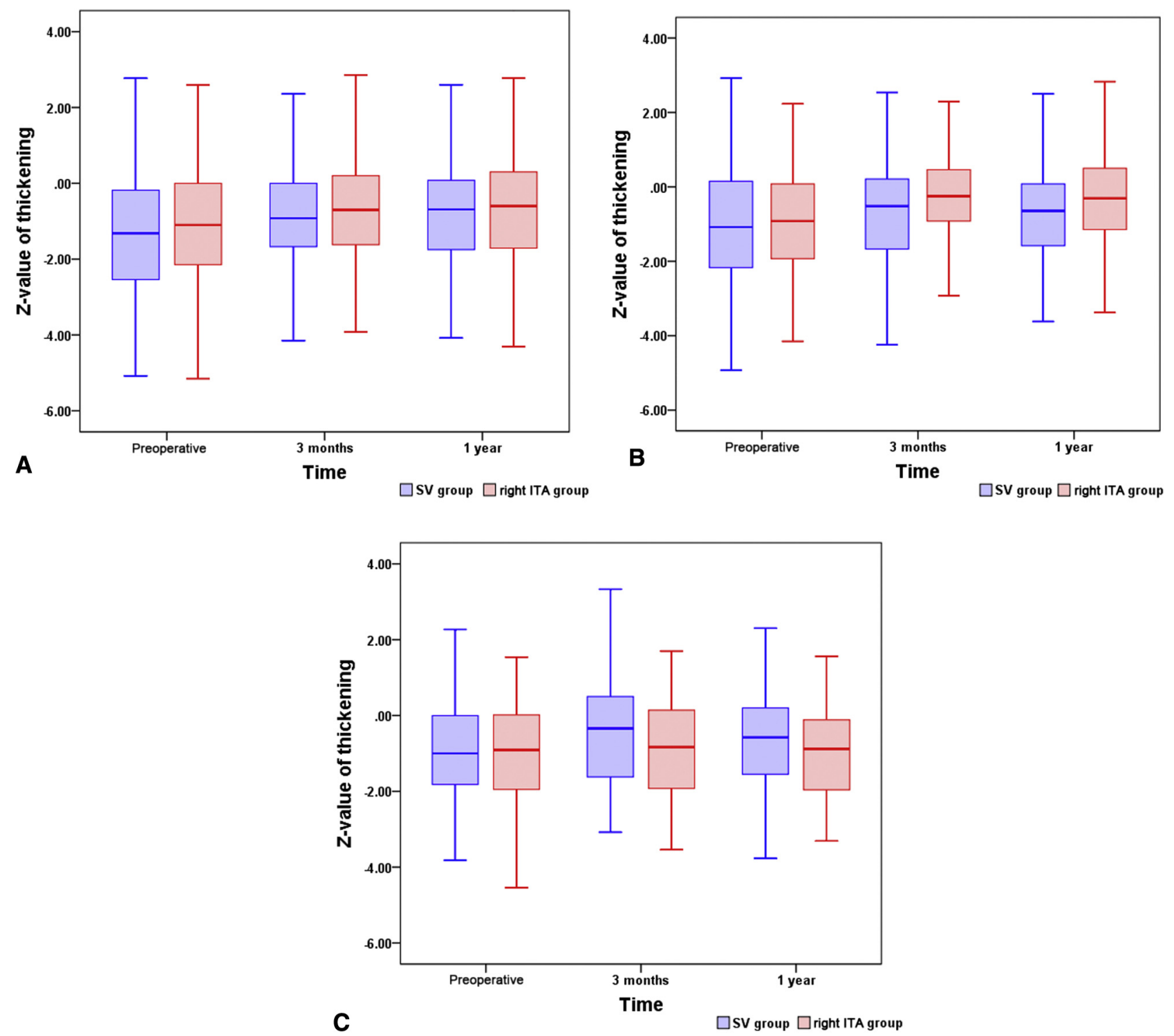

FIGURE 4. Improvement of myocardial thickening (Z-values) in the (A) LAD; (B) LCX; and (C) RCA territories in the SV and RITA groups, preoperatively, and at 3 months and 1 year postoperatively. (The central box represents the values from the lower to the upper quartile, and the middle line represents the median. A line extends from the minimum to the maximum value). SV, Saphenous vein; RITA, right internal thoracic artery.

selected from those enrolled in a randomized controlled trial. Second, because the SPECT data were not drawn from all the participants of the SAVE RITA trial, selection bias could affect our results. Third, a 20 -segment model was adopted for regional analysis, and 16 segments were subtended to the left coronary artery territory and 4 segments to the RCA territory, respectively. The coronary artery dominance pattern of individual patients was not considered. In addition, values from various segments were averaged and different numbers of segments were analyzed in each patient, without weighting.
Fourth, the statistical model in this study is complex. A further analysis of the current results, such as a higher reversibility score value in the LCX territory than in the LAD territory, and a significant interaction between the conduit type and coronary artery territories in myocardial thickening, is warranted. Fifth, whether the native coronary artery disease was highly progressed or newly developed was not considered in the analysis, nor was the severity of the target vessel stenosis. Sixth, the 1-year results of myocardial perfusion and thickening improvement did not provide sufficient data to reach a definite conclusion on the comparability of the SV composite graft with the right 
TABLE 4. Mixed-effect regression model on changes in Z-values of myocardial thickening, according to the coronary artery territory

\begin{tabular}{|c|c|c|c|}
\hline Variables & $\begin{array}{c}\text { Estimate } \\
(\beta)\end{array}$ & $95 \%$ CI & $\begin{array}{c}P \\
\text { value }\end{array}$ \\
\hline \multicolumn{4}{|l|}{ Type of conduit $(\mathrm{ref}=\mathrm{SV})$} \\
\hline Right ITA & -0.159 & -0.570 to 0.252 & .448 \\
\hline \multicolumn{4}{|l|}{ Time (ref $=$ preoperation) } \\
\hline $3 \mathrm{mo}$ & 0.487 & 0.383 to 0.590 & $<.001$ \\
\hline $1 \mathrm{y}$ & 0.449 & 0.346 to 0.552 & $<.001$ \\
\hline Number of distal anastomoses & -0.097 & -0.214 to 0.020 & .103 \\
\hline \multicolumn{4}{|l|}{$\begin{array}{l}\text { Coronary artery territory } \\
\qquad(\text { ref }=\mathrm{LAD})\end{array}$} \\
\hline LCX & -0.047 & -0.189 to 0.095 & .519 \\
\hline RCA & -0.062 & -0.249 to 0.126 & .520 \\
\hline \multicolumn{4}{|l|}{ Group by coronary artery territory } \\
\hline Right ITA at LCX & 0.393 & 0.192 to 0.594 & $<.001$ \\
\hline Right ITA at RCA & 0.063 & -0.221 to 0.347 & 663 \\
\hline
\end{tabular}

$C I$, Confidence interval; ref, reference; $S V$, saphenous vein; ITA, internal thoracic artery; $L A D$, left anterior descending coronary artery; $L C X$, left circumflex coronary artery; $R C A$, right coronary artery.

ITA composite graft. To do so, our study needs to be extended to several years after surgery.

\section{Conflict of Interest Statement}

Authors have nothing to disclose with regard to commercial support.

The authors thank the Medical Research Collaborating Center, Seoul National University Hospital, for statistical consultation.

\section{References}

1. Cox JL, Chiasson DA, Gotlieb AI. Stranger in a strange land: the pathogenesis of saphenous vein graft stenosis with emphasis on structural and functional differences between veins and arteries. Prog Cardiovasc Dis. 1991; 34:45-68.

2. Loop FD, Lytle BW, Cosgrove DM, Stewart RW, Goormastic M, Williams GW, et al. Influence of the internal-mammary-artery graft on 10-year survival and other cardiac events. N Engl J Med. 1986;314:1-6.

3. Cameron A, Davis KB, Green G, Schaff HV. Coronary bypass surgery with internal thoracic-artery grafts-effects on survival over a 15-year period. N Engl J Med. 1996;334:216-20.

4. Souza DS, Johansson B, Bojö L, Karlsson R, Geijer H, Filbey D, et al. Harvesting the saphenous vein with surrounding tissue for $\mathrm{CABG}$ provides long-term graft patency comparable to the left internal thoracic artery: results of a randomized longitudinal trial. J Thorac Cardiovasc Surg. 2006;132:373-8.
5. Hwang HY, Kim MA, Seo JW, Kim KB. Endothelial preservation of the minimally manipulated saphenous vein composite graft: histologic and immunochemical study. J Thorac Cardiovasc Surg. 2012;144:690-6.

6. Hwang HY, Kim JS, Oh SJ, Kim KB. A randomized comparison of the Saphenous Vein Versus Right Internal Thoracic Artery as a Y-Composite Graft (SAVE RITA) trial: early results. J Thorac Cardiovasc Surg. 2012;144:1027-33.

7. Kim KB, Hwang HY, Hahn S, Oh SJ, Kim JS. A randomized comparison of the Saphenous VEin versus Right Internal Thoracic Artery as a Y-composite graft (SAVE RITA trial): one-year angiographic results and mid-term clinical outcomes. J Thorac Cardiovasc Surg. 2014;148:901-7.

8. Paeng JC, Lee DS, Kang WJ, Lee BI, Kim KB, Chung JK, et al. Time course of functional recovery after coronary artery bypass grafting surgery according to the preoperative reversibility of perfusion impairment on myocardial SPECT. Eur J Nucl Med Mol Imaging. 2005;32:70-4.

9. Cho KR, Hwang HY, Kang WJ, Lee DS, Kim KB. Progressive improvement of myocardial perfusion after off pump revascularization with bilateral internal thoracic arteries: comparison of early versus 1-year postoperative myocardial single photon emission computed tomography. J Thorac Cardiovasc Surg. 2007; $133: 52-7$

10. Sharir T, Berman DS, Waechter PB, Areeda J, Kavanaqh PB, Gerlach J, et al. Quantitative analysis of regional motion and thickening by gated myocardial perfusion SPECT: normal heterogeneity and criteria for abnormality. J Nucl Med. 2001;42:1630-8

11. Goldman S, Sethi GK, Holman W, Thai H, McFalls E, Ward HB, et al. Radial artery grafts vs saphenous vein grafts in coronary artery bypass surgery: a randomized trial. JAMA. 2011:305:167-74.

12. Deb S, Cohen EA, Singh SK, Une D, Laupacis A, Fremes SE, et al. Radial artery and saphenous vein patency more than 5 years after coronary artery bypass surgery: results from RAPS (Radial Artery Patency Study). J Am Coll Cardiol. 2012;60:28-35

13. Tedoriya T, Kawasuji M, Sakakibara N, Ueyama K, Watanabe Y. Pressure characteristics in arterial grafts for coronary bypass surgery. Cardiovasc Surg. 1995; $3: 381-5$.

14. Tsui JC, Souza DS, Filbey D, Bomfim V, Dashwood MR. Preserved endothelial integrity and nitric oxide synthase in saphenous vein grafts harvested by a 'no-touch' technique. Br J Surg. 2001;88:1209-15.

15. Gaudino M, Toesca A, Maggiano N, Pragliola C, Possati G. Localization of nitric oxide synthase type III in the internal thoracic and radial arteries and the great saphenous vein: a comparative immunohistochemical study. J Thorac Cardiovasc Surg. 2003;125:1510-5.

16. Liu ZG, Ge ZD, He GW. Difference in endothelium-derived hyperpolarizing factormediated hyperpolarization and nitric oxide release between human internal mammary artery and saphenous vein. Circulation. 2000;102:III296-301.

17. Kim CY, Hwang HY, Paeng JC, Kim KB. Improved myocardial perfusion and thickening after off-pump revascularization: 5-year follow-up. Ann Thorac Surg. 2009;88:1419-25.

18. He GW. Contractility of the human internal mammary artery at the distal section increases toward the end. Emphasis on not using the end of the IMA for grafting. J Thorac Cardiovasc Surg. 1993;106:406-11.

19. He GW, Acuff TE, Yang CQ, Ryan WH, Mack MJ. Middle and proximal sections of the human internal mammary artery are not "passive conduits" J Thorac Cardiovasc Surg. 1994;108:741-6.

Key Words: off-pump CABG, saphenous vein, myocardial SPECT 